\title{
Relation between Hepatitis B Carrier Status and Antibody against Synthetic Plasmodium falciparum Erythrocyte Surface (pf155 - RESA) Antigen
}

\author{
Francisco José Dutra Souto/ ${ }^{+}$, Cor Jésus Fernandes Fontes, Ana Maria Coimbra Gaspar*
}

Núcleo de Estudos de Doenças Infecciosas e Tropicais, Faculdade de Ciências Médicas, Universidade Federal de Mato Grosso, Caixa Postal no 3241, 78048-790 Cuiabá, MT, Brasil *Departamento de Virologia, Instituto Oswaldo Cruz-Fiocruz,

Rio de Janeiro, RJ, Brasil

A survey on Plasmodium infection was carried out in gold mine camps located in the Brazilian Amazon. Antibody against $\mathrm{P}$. falciparum ring-infected erythrocyte surface antigen (RESA) was quantified by an enzyme-immunoassay in order to assess $\mathrm{P}$. falciparum exposure. Hepatitis $B$, a common infection in this area, was also investigated by serologic markers. Among 520 sampled subjects, 517 (99.4\%) admitted previous symptomatic malaria, 106 (20.4\%) had positive thick smears for malaria, $82.9 \%$ had HBV markers, and $7.1 \%$ were HBsAg positive. Anti-RESA titers was significantly lower in HBV carriers than in people with resolved HBV infection suggesting that the anti-RESA immune response could be supressed by $H B V$ carrier status. Moreover, immunedeficient responses to both infections may take place in some subjects causing concomitant lower anti-RESA response and incapacity to clear HBV.

Key words: malaria falciparum - malaria antigen - hepatitis B virus - Brazilian Amazon

Falciparum malaria and hepatitis B virus (HBV) infections are quite common in the Amazon Basin. Recent reports have shown that this situation also prevails in the southernmost part of the Brazilian Amazon, corresponding to the State of Mato Grosso (Andrade et al. 1995, Souto et al. 1998).

A cross-sectional survey of Plasmodium infection was carried out in inhabitants of gold mine camps located in the county of Apiacás, north of Mato Grosso, as reported elsewhere (Souto et al. 2001). Reactivity to antibody against $P$. falciparum ring-infected erythrocyte surface antigen (RESA) was quantified by an enzyme-immunoassay (EIA) in order to assess $P$. falciparum exposure. Gold miners generally have a high prevalence of malaria and $\mathrm{HBV}$ infection and are considered to facilitate the spread of both diseases throughout the region (Andrade et al. 1995, Souto et al. 1998). To investigate any relation between malaria and HBV infection the participants were tested for HBV markers as well. The ethical and methodological aspects of this survey were approved by the Federal University of Mato Grosso Research Ethical Committee. The objectives of the study were explained to all participants and informed consent was obtained.

This study was performed between March and June 1996. There were 16 gold mine camps in the county of Apiacás. Five hundred and twenty out of 569 inhabitants of the camps were interviewed and bled. Male subjects

${ }^{+}$Corresponding author. Fax: +55-65-6157302. E-mail: fsouto@ nutecnet.com.br Received 16 April 2001

Accepted 5 November 2001 comprised $442(85 \%)$ of the overall sample and their age ranged from 3 to 66 years $($ mean $=32$ ). Most of them (79.6\%) were aged between 20 and 40 years.

Thick blood smears for identification of Plasmodium were prepared. Aliquots of serum were sent to the Department of Virology, Instituto Oswaldo Cruz, Rio de Janeiro, where they were analyzed for HBV surface antigen and antibody (HBsAg and anti-HBs, respectively), and total antibodies against HBV core antigen (anti-HBc), by an EIA from Organon Teknika-Hepanostika, Boxtel, The Netherlands.

Antibodies against $P$. falciparum were measured by an EIA using RESA produced by Bachem (California, USA), H6215, Lot 119285. This test was standardised and performed at the Blood Bank of Universidade Federal de Mato Grosso, Cuiabá, Brazil. A synthetic peptide $\{[(\mathrm{CTG}-$ $\left.\left.\left.(\mathrm{EENV})_{4}-\mathrm{OH}\right)\right]_{2}\right\}$ reproducing one of the repeats present in the RESA molecule was used in EIA. Micro-EIA plates were coated with $100 \mu \mathrm{l} /$ well of the synthetic peptide $(2.5$ $\mathrm{mg} / \mathrm{ml}$ in phosphate-buffered saline-PBS) and incubated overnight at $4^{\circ} \mathrm{C}$. After spray-wash with PBS-Tween 20 $(0.05 \%$ PBS-T), plates were blocked with $5 \%$ non-fat powdered milk in PBS-T and incubated for $2 \mathrm{~h}$ at $37^{\circ} \mathrm{C}$. After washing plasma samples were added (100 $\mu \mathrm{l} /$ well $)$ at a dilution of $1: 50$. After $1 \mathrm{~h}$ incubation at $37^{\circ} \mathrm{C}$ plates were washed again and peroxidase-conjugated goat anti-human IgG was used to detect bound antibodies. As the chromogenic substrate we used 2,2'-azino-di-(3-etilbenztiazoline sulfonate). Optical densities were read at $420 \mathrm{~nm}$.

Thick blood smears were positive in $106(20.4 \%)$ out of the 520 subjects ( $P$. falciparum, 56; $P$. vivax, 47; and $P$. malarie 3); 517 (99.4\%) admitted previous symptomatic malarial episodes; 431 (82.9\%) had been exposed to HBV: 
$37(7.1 \%)$ were HBsAg carriers and 394 had previous infection markers (anti-HBc plus anti-HBs, 297, or anti-HBc as the sole marker, 97).

The mean anti-RESA titers of the overall sample was 0.806 , ranging from 0 to 3.256 . The mean anti-RESA titers of the HBsAg carriers (0.451) was significantly lower than the mean of the rest of subjects $(0.832)(\mathrm{P}<0.01)$ and this difference remained statistically significant $(\mathrm{P}<0.001)$ after multiple linear regression analysis (Stata 5.0, Stata Corporation, Texas, USA) adjusting for age and time living in the study area. This last variable was also associated with the anti-RESA titers but in a positive way $(\mathrm{P}<$ $0.05)$. There was no association between current Plasmodium infection and HBV carrier status ( 8 out of $37,21.6 \%$, vs 98 out of $483,20.3 \%$ ).

Anti-RESA (pf155) is an antibody that appears following intense and frequent exposure to $P$. falciparum. Usually anti-RESA concentration is higher in older individuals and among those living longer in malarial areas (Baird et al. 1991). High anti-RESA reactivity may be associated with acquired protection against malaria (Migot et al. 1993, Achidi et al. 1995, Al-Yaman et al. 1997), although some studies have shown different findings (Deloron \& Cot 1990, Astagneau et al. 1995).

Malaria and HBV infections are common in vast tropical areas. Consequently, these infections overlap frequently. In this study most of the surveyed people had already been infected by both. The relation between these two infections has been investigated in some countries. Thursz et al. (1995) showed an association between HBV carriage and more severe malaria cases in Gambian children and suggested that reduced level of HLA antigen expression on hepatocytes infected by HBV could impair clearance of liver stage malaria parasites. In Thailand, Brown et al. (1992) verified that chronic asymptomatic malaria falciparum may be accompanied by sustained periods of $\mathrm{HBV}$ reactivation. In our study, $\mathrm{HBsAg}$-positive subjects as well as HBsAg-negative ones had similar number of malaria episodes ( $\mathrm{P}=0.8$, data not shown), so that similar anti-RESA reactivity would be expected. However, anti-RESA reactivity were significantly lower in HBsAg carriers than in people with cleared HBV even after adjustment for age and time living in the study area. This negative association could have resulted from some other confounder. To investigate this hypothesis several demographic, epidemiological and behavioral factors, such sharing needles, men who have sex with men and previous sexual transmitted diseases were analyzed. No other variable was inversely associated to anti-RESA response level. Human immunodeficiency virus infection status of the sampled subjects was not assessed since it was not the main objective of the study.
These findings suggest that the anti-RESA immune response could be suppressed by HBV carrier status. However, immunedeficient responses to both infections may take place in some subjects causing concomitant lower anti-RESA concentration and incapacity to clear HBV. Further studies concerning relation between $P$. falciparum and HBV infection are needed to assess its potential influence in chronic hepatic disease in tropical areas.

\section{REFERENCES}

Achidi EA, Perlmann H, Salimonu LS, Perlmann P, Walker O, Azuzu MC 1995. A longitudinal study of seroreactivities to $P$. falciparum antigens in Nigerian infants during their first year of life. Acta Trop 59: 173-183.

Al-Yaman F, Genton B, Taraika J, Anders R, Alpers MP 1997. Association between cellular response (IL-4) to RESA/Pf155 and protection from clinical malaria among Papua New Guinean children living in a malaria endemic area. Parasite Immunol 19: 249-254.

Andrade AL, Martelli CM, Oliveira RM, Arias JR, Zicker F, Pang L 1995. High prevalence of asymptomatic malaria in gold mining areas in Brazil. Clin Infect Dis 20: 475.

Astagneau P, Roberts JM, Steketel RW, Wirima JJ, Lepers JP, Deloron P 1995. Antibodies to a P. falciparum blood-stage antigen as a tool for predicting the protection levels of two malaria-exposed populations. Am J Trop Med Hyg 53: 2328.

Baird JK, Jones TR, Danudirgo EW, Annis BA, Bangs MJ, Basri H, Purnomo, Masbar S 1991. Age-dependent acquired protection against $P$. falciparum in people having two years exposure to hyperendemic malaria. Am J Trop Med Hyg 45: 65-76.

Brown AE, Mongkolsirichaikul D, Innis B, Snitbhan R, Webster HK 1992. Falciparum malaria modulates viremia in chronic hepatitis B virus infection. J Infect Dis 166: 1465-1466.

Deloron P, Cot M 1990. Antibodies to the ring-infected erythrocyte surface antigen and the circumsporozoite protein of $P$. falciparum in a rural community from Burkina Faso. Trans R Soc Trop Med Hyg 84: 191-195.

Migot F, Chougnet C, Raharimalala L, Astagneau P, Lepers JP, Deloron P 1993. Human immune responses to the $P$. falciparum ring-infected erythrocyte surface antigen (Pf 155 RESA) after a decrease in malaria transmission in Madagascar. Am J Trop Med Hyg 48: 432-439.

Souto FJD, Fontes CJF, Gaspar AMC, Lyra LGC 1998. Hepatitis B virus in immigrants to the southern Brazilian Amazon. Trans R Soc Trop Med Hyg 92: 282-284.

Souto FJD, Fontes CJF, Gaspar AMC 2001. Prevalence of hepatitis $\mathrm{B}$ and $\mathrm{C}$ virus markers among malaria-exposed gold miners in Brazilian Amazon. Mem Inst Oswaldo Cruz 96: 751-756.

Thursz MR, Kwiatkowski D, Torok ME, Allsopp CAM, Greenwood BM, Whittle HC, Thomas HC, Hill AVS 1995. Association of hepatitis B surface antigen carriage with severe malaria in Gambian children. Nature Medicine 1: 374375 . 